\title{
Men Have a Stronger Monocyte-Derived Cytokine Production Response upon Stimulation with the Gram-Negative Stimulus Lipopolysaccharide than Women: A Pooled Analysis Including 15 Study Populations
}

\author{
Karel G.M. Beenakker ${ }^{a, b}$ Rudi G.J. Westendorp ${ }^{a, c}$ Anton J.M. de Craen ${ }^{a}$ \\ Sijia Chen ${ }^{a, d}$ Yotam Raz ${ }^{a, e}$ Bart E.P.B. Ballieux ${ }^{f}$ Rob G.H.H. Nelissen ${ }^{g}$ \\ Alexander F.L. Later ${ }^{\mathrm{h}}$ Tom W. Huizinga ${ }^{i}$ Pieternella E. Slagboom ${ }^{\mathrm{e}}$ \\ Dorret I. Boomsmaj Andrea B. Maierk, I

\begin{abstract}
${ }^{a}$ Department of Gerontology and Geriatrics, Leiden University Medical Center, Leiden, The Netherlands; ${ }^{b}$ Rivierduinen Mental Health Institute, Leiden, The Netherlands; ${ }^{C}$ Department of Public Health and Center for Healthy Aging, University of Copenhagen, Copenhagen, Denmark; ${ }^{d}$ Department of Experimental Immunology, Academic Medical Center, Amsterdam, The Netherlands; ${ }^{\text {eDepartment }}$ of Medical Statistics, Molecular Epidemiology, Leiden University Medical Center, Leiden, The Netherlands; ${ }^{\mathrm{f}}$ Department of Clinical Chemistry and Laboratory Medicine, Leiden University Medical Center, Leiden, The Netherlands; ${ }^{9}$ Department of Orthopaedics, Leiden University Medical Center, Leiden, The Netherlands; h Department of Cardiothoracic Surgery, Leiden University Medical Center, Leiden, The Netherlands; ' Department of Rheumatology, Leiden University Medical Center, Leiden, The Netherlands; ${ }^{j}$ Department of Biological Psychology, VU University Amsterdam, Amsterdam, The Netherlands; ${ }^{\mathrm{k}}$ Department of Medicine and Aged Care, @AgeMelbourne, Royal Melbourne Hospital, University of Melbourne, Melbourne, VIC, Australia; 'Department of Human Movement Sciences, @AgeAmsterdam, Faculty of Behavioural and Movement Sciences, Vrije Universiteit
\end{abstract} \\ Amsterdam, Amsterdam Movement Sciences, Amsterdam, The Netherlands
}

\section{Keywords}

Innate immunity · Cytokines · Gender · Sex ·

Lipopolysaccharide · Blood

\begin{abstract}
The incidence of bacterial infections and sepsis, as well as the mortality risk from sepsis, is sex specific. These clinical findings have been attributed to sex differences in immune responsiveness. The aim of the present study was to investigate sex differences in monocyte-derived cytokine production response upon stimulation with the gram-negative stimulus lipopolysaccharide (LPS) using cytokine data from 15 study populations. Individual data on ex vivo cytokine
\end{abstract}

\begin{tabular}{ll}
\hline KARGER & ( 2019 The Author(s) Karger \\
& Published by S. Karger AG, Basel Open access \\
E-Mail karger@karger.com & This article is licensed under the Creative Commons Attribution- \\
www.karger.com/jin & $\begin{array}{l}\text { NonCommercial-NoDerivatives 4.0 International License (CC BY- } \\
\text { NC-ND) (http://www.karger.com/Services/OpenAccessLicense). } \\
\text { Usage and distribution for commercial purposes as well as any dis- } \\
\text { tribution of modified material requires written permission. }\end{array}$
\end{tabular}

production response upon stimulation with LPS in whole blood were available for 4,020 subjects originating from these 15 study populations, either from the general population or from patient populations with specific diseases. Men had a stronger cytokine production response than women to LPS for tumour necrosis factor-a, interleukin (IL)-6, IL-12, IL-1 $\beta$, IL-1RA, and IL-10, but not for interferon- $\gamma$. The granulocyte-macrophage colony-stimulating factor production response was lower in men than in women. These sex differences were independent of chronological age. As men had higher monocyte concentrations, we normalized the cytokine production responses for monocyte concentration. Af-

\section{A.J.M. de Craen deceased 17 January 2016.}


ter normalization, the sex differences in cytokine production response to LPS disappeared, except for IL-10, for which the production response was lower in men than in women. A sex-based approach to interpreting immune responsiveness is crucial.

(c) 2019 The Author(s)

Published by S. Karger AG, Basel

\section{Introduction}

Although the incidence of bacterial infection [1] and sepsis [2] is higher among men than among women, men less often develop autoimmune diseases [3] and have a lower mortality risk from sepsis [4]. These clinical findings have been attributed to sex differences in immune responsiveness [5], which is hypothesized to be the evolutionary consequence of sex differences in reproductive strategies [6].

Immune responsiveness can be assessed by a whole blood stimulation assay, which measures the amount of cytokines produced by immune cells upon stimulation with the gram-negative stimulus lipopolysaccharide (LPS). This stimulation assay is well reproducible [7] and primarily assesses subjects' cytokine production by monocytes [8], which is under tight genetic control [9]. A higher proinflammatory cytokine and a lower anti-inflammatory production response upon stimulation with LPS have been associated with survival from meningococcal infection [10], a lower incidence of systemic lupus erythematosus [11], and less severe progression of multiple sclerosis [12]. Several studies have reported a stronger monocyte-derived cytokine production response upon stimulation with LPS in men than in women [1320], although others have found no sex differences [20$22]$. Furthermore, these sex differences were only found in relatively young and healthy subjects [13-17, 20, 23] and not in older subjects [14, 22]. Moreover, no sex differences were found in patient populations with specific diseases, such as patients after elective coronary stent placement [24], after severe blunt trauma [25], or before and after abdominal surgery [26]. However, most of these studies were performed with a small number of subjects and investigated only a limited number of cytokines, which hampers a conclusive and comprehensive interpretation of sex differences in cytokine production response upon stimulation with LPS.

In the last 18 years, the assay for measuring the cytokine production response upon stimulation with LPS has been performed in the same laboratory in a standardized manner using the same techniques for 15 study popula- tions. This allowed us to perform a meta-analysis of sex differences in cytokine production response upon stimulation with LPS in an unprecedentedly large number of subjects. The included subjects were young, middle-aged, or older adults from the general population or had specific diseases like osteoarthritis, rheumatoid arthritis, multiple sclerosis, systemic lupus erythematosus, or cardiac diseases warranting cardiac surgery. We first investigated the cytokine production response for tumour necrosis factor- $\alpha$ (TNF- $\alpha$ ), interleukin (IL)-6, IL-12, IL-1 $\beta$, IL-1RA, IL-10, interferon- $\gamma$ (IFN- $\gamma)$, and granulocytemacrophage colony-stimulating factor (GM-CSF) in men compared to women. Secondly, we investigated whether the sex differences in cytokine production response were different in various age groups. Thirdly, we explored whether the observed differences in cytokine production response between men and women were attributable to differences in monocyte concentrations.

\section{Materials and Methods}

\section{Study Populations}

We included 15 study populations for which data on the cytokine production response upon stimulation with the gram-negative stimulus LPS had been generated at our laboratory over the last 18 years. The key references for the studies reporting on these populations are given in Table 1.

\section{Cytokine Production Response}

The cytokine production response was measured using whole blood samples upon stimulation with LPS, as described elsewhere [7]. In brief, venous blood samples were drawn and collected in heparinized tubes. The samples were then diluted with RPMI 1640 and incubated after addition of $E$. coli-derived LPS at $37^{\circ} \mathrm{C}$ and $5 \%$ $\mathrm{CO}_{2}$ for $24 \mathrm{~h}$. Table 2 shows the LPS concentration used and the period of incubation for each study population. After centrifugation, the supernatants were stored at $-80^{\circ} \mathrm{C}$ until they were assayed for TNF- $\alpha$, IL-6, IL-1 $\beta$, IL-10, and IFN- $\gamma$ using PeliKine Compact ELISA kits (Sanquin, Amsterdam, The Netherlands). IL-12, IL1RA, and GM-CSF were assayed using ELISA kits from R\&D Systems (Minneapolis, MN, USA). Before 2010, for IL-12 and IL-1RA, ELISA kits from BioSource (Louvain, Belgium) had been used. Table 2 shows the cytokines tested for each study population and the key references for additional available information on the studies' materials and methods. Subjects with an unstimulated TNF- $a$ concentration above $100 \mathrm{pg} / \mathrm{mL}$ were excluded from further analysis due to concerns over possible contamination or acute infection $(n=27)$.

\section{Hematologic Measurements}

Leukocyte, neutrophil, lymphocyte, monocyte, eosinophil, and basophil concentrations were measured in venous blood samples using a Sysmex XE-2100 Hematology Analyzer (Sysmex, EttenLeur, The Netherlands). Table 2 shows for which study populations these hematologic measurements were available. 
Table 1. Characteristics of the included study populations

\begin{tabular}{|c|c|c|c|c|c|c|}
\hline Study name & Characteristics of the subjects & $\begin{array}{l}\text { Key Ref. } \\
\text { for study } \\
\text { design }\end{array}$ & $\begin{array}{l}\text { Subjects, } \\
n\end{array}$ & $\begin{array}{l}\text { Family } \\
\text { clusters, } \\
n\end{array}$ & $\begin{array}{l}\text { Mean age } \\
\text { (SD) [min.- } \\
\text { max.], years }\end{array}$ & $\begin{array}{l}\text { Men, } \\
\%\end{array}$ \\
\hline \multicolumn{7}{|c|}{ General population } \\
\hline Myoage young & $\begin{array}{l}\text { Young subjects living independently, socially active, and free } \\
\text { from disease that impairs mobility levels }\end{array}$ & {$[45]$} & 35 & $\mathrm{n} / \mathrm{a}$ & $\begin{array}{l}21(3) \\
{[18-30]}\end{array}$ & 42.9 \\
\hline YNTR & $\begin{array}{l}\text { Young (Y) twins from the Netherlands Twin Register (NTR) } \\
\text { and their first-degree relatives }\end{array}$ & {$[46]$} & 161 & 74 & $\begin{array}{l}27(4) \\
{[15-39]}\end{array}$ & 47.2 \\
\hline $\begin{array}{l}\text { Meningitis } \\
\text { relatives }\end{array}$ & $\begin{array}{l}\text { First-degree relatives of patients admitted to Leiden } \\
\text { University Medical Center because of meningococcal disease }\end{array}$ & {$[10]$} & 180 & 60 & $\begin{array}{l}31(16) \\
{[3-71)}\end{array}$ & 48.3 \\
\hline $\begin{array}{l}\text { MS-SLE } \\
\text { relatives }\end{array}$ & $\begin{array}{l}\text { First-degree relatives of patients with multiple sclerosis (MS) } \\
\text { or systemic lupus erythematosus (SLE) }\end{array}$ & {$[12]$} & 550 & 177 & $\begin{array}{l}45(17) \\
{[3-88]}\end{array}$ & 44.5 \\
\hline Ghana & $\begin{array}{l}\text { Subjects living in a remote, rural, and underdeveloped area } \\
\text { in the Upper East Region of Ghana in West Africa }\end{array}$ & {$[47]$} & 627 & $\mathrm{n} / \mathrm{a}$ & $\begin{array}{l}47(21) \\
{[6-95]}\end{array}$ & 26.5 \\
\hline ANTR & $\begin{array}{l}\text { Middle-aged (A) twins from the Netherlands Twin Register } \\
\text { (NTR) and first-degree relatives }\end{array}$ & {$[46]$} & 140 & 64 & $\begin{array}{l}50(7) \\
{[29-68]}\end{array}$ & 45.0 \\
\hline LLS & $\begin{array}{l}\text { Subjects of the Leiden Longevity Study (LLS) including off- } \\
\text { spring of long-lived siblings and the spouses of the offspring }\end{array}$ & {$[33]$} & 392 & 322 & $\begin{array}{l}63(7) \\
{[42-81]}\end{array}$ & 49.7 \\
\hline Myoage old & $\begin{array}{l}\text { Old subjects living independently, socially active, and free } \\
\text { from disease that impairs mobility levels }\end{array}$ & {$[45]$} & 74 & $\mathrm{n} / \mathrm{a}$ & $\begin{array}{l}74(3) \\
{[70-80]}\end{array}$ & 51.4 \\
\hline PROSPER & $\begin{array}{l}\text { Participants of the Prospective Study of Pravastatin in the } \\
\text { Elderly at Risk (PROSPER) including subjects with a history } \\
\text { of, or risk factors for, vascular disease }\end{array}$ & {$[48]$} & 403 & $\mathrm{n} / \mathrm{a}$ & $\begin{array}{l}75(3) \\
{[70-83]}\end{array}$ & 53.6 \\
\hline Leiden 85-plus & $\begin{array}{l}\text { Inhabitants of Leiden, the Netherlands, aged } 85 \text { years at the } \\
\text { start of the study }\end{array}$ & {$[49]$} & 552 & $\mathrm{n} / \mathrm{a}$ & $\begin{array}{l}85(-) \\
{[85-85]}\end{array}$ & 33.2 \\
\hline \multicolumn{7}{|l|}{ Specific diseases } \\
\hline MS-SLE & $\begin{array}{l}\text { Patients with multiple sclerosis (MS) or systemic lupus } \\
\text { erythematosus (SLE) }\end{array}$ & {$[12]$} & 152 & $\mathrm{n} / \mathrm{a}$ & $\begin{array}{l}46(14) \\
{[16-84]}\end{array}$ & 28.3 \\
\hline BEST & $\begin{array}{l}\text { Patients with recent-onset rheumatoid arthritis Before Start } \\
\text { (BEST) with disease-modifying antirheumatic drugs }\end{array}$ & {$[53]$} & 73 & $\mathrm{n} / \mathrm{a}$ & $\begin{array}{l}55(15) \\
{[23-80]}\end{array}$ & 32.9 \\
\hline Cardiac surgery & $\begin{array}{l}\text { Adult patients admitted to the Department of } \\
\text { Cardiothoracic Surgery of the Leiden University Medical } \\
\text { Center, included the day before surgery }\end{array}$ & {$[50]$} & 199 & $\mathrm{n} / \mathrm{a}$ & $\begin{array}{l}64(12) \\
{[26-86]}\end{array}$ & 72.4 \\
\hline GARP & $\begin{array}{l}\text { Patients with osteoarthritis and their relatives with joint } \\
\text { complains which were included for a study on Genetics, } \\
\text { Arthrosis and Progression (GARP) }\end{array}$ & {$[51]$} & 370 & 188 & $\begin{array}{l}71(8) \\
{[52-89]}\end{array}$ & 18.6 \\
\hline PRALINE & $\begin{array}{l}\text { Patients after knee replacement surgery studied for the } \\
\text { Prediction of Aseptic Implant Loosening due to Innate } \\
\text { Immunity (PRALINE) }\end{array}$ & {$[52]$} & 112 & $\mathrm{n} / \mathrm{a}$ & $\begin{array}{l}73(10) \\
{[43-90]}\end{array}$ & 18.8 \\
\hline
\end{tabular}

All studies were performed in the Netherlands, except for the Ghana Study, which was performed in Ghana. The number of family clusters refers to the number of independent observations corrected for family relationships between subjects. n/a, not available.

Statistical Analyses

Statistical analyses were performed using IBM SPSS Statistics version 20 and StataCorp Stata/SE version 12.0. For each subject, the cytokine production response values were natural $\log (\ln )$ transformed due to skewness. For each study population, the difference in cytokine production response between men and women was calculated using linear regression analyses with ln-transformed cytokine production response as the dependent variable 
Table 2. Method of whole blood stimulation and availability of cytokine production response per study population

\begin{tabular}{|c|c|c|c|c|}
\hline $\begin{array}{l}\text { Name of the study } \\
\text { population }\end{array}$ & \multicolumn{2}{|c|}{$\begin{array}{ll}\text { Key Ref. for } & \text { LPS } \\
\text { methods } & \text { concentration }\end{array}$} & $\begin{array}{l}\text { Monocyte } \\
\text { concentration } \\
\text { available }\end{array}$ & Cytokine production response \\
\hline
\end{tabular}

\section{General population}

Myoage young

YNTR

Meningitis relatives

MS-SLE relatives

Ghana

ANTR

LLS

Myoage old

PROSPER

Leiden 85-plus

Specific diseases

MS-SLE

BEST

Cardiac surgery

GARP

PRALINE

$\begin{array}{lll}\mathrm{n} / \mathrm{a} & 10 \mu \mathrm{g} / \mathrm{mL} & \mathrm{v} \\ {[9]} & 10 \mathrm{ng} / \mathrm{mL} & \\ {[10]} & 1 \mu \mathrm{g} / \mathrm{mL} & \\ {[12]} & 10 \mathrm{ng} / \mathrm{mL} & \\ {[47]} & 10 \mu \mathrm{mL} & \\ {[9]} & 10 \mathrm{ng} / \mathrm{mL} & \\ {[33]} & 10 \mathrm{ng} / \mathrm{mL} & \mathrm{v} \\ \mathrm{n} / \mathrm{a} & 10 \mu \mathrm{mL} / \mathrm{mL} & \mathrm{v} \\ {[48]} & 10 \mathrm{ng} / \mathrm{mL} & \\ {[49]} & 10 \mathrm{ng} / \mathrm{mL} & \end{array}$

\section{$10 \mathrm{ng} / \mathrm{mL}$}

$10 \mathrm{ng} / \mathrm{mL}$

$10 \mathrm{ng} / \mathrm{mL}$

$\begin{array}{ll}{[53]} & 10 \mathrm{ng} / \mathrm{mL} \\ \mathrm{n} / \mathrm{a} & 10 \mathrm{ng} / \mathrm{mL} \\ {[35]} & 10 \mathrm{ng} / \mathrm{mL}\end{array}$

$\mathrm{n} / \mathrm{a} \quad 10 \mu \mathrm{g} / \mathrm{mL}$

$\mathrm{v}$
$\mathrm{v}$
$\mathrm{v}^{\mathrm{a}}$
$\mathrm{v}$
$\mathrm{V}$
$\mathrm{V}$
$\mathrm{V}$
$\mathrm{V}$
$\mathrm{v}$
$\mathrm{v}^{\mathrm{b}}$

$\begin{array}{ll}\mathrm{v} & \mathrm{V} \\ \mathrm{V} & \\ \mathrm{V} & \mathrm{v} \\ \mathrm{V} & \\ \mathrm{V} & \mathrm{v} \\ \mathrm{V} & \mathrm{V} \\ \mathrm{V} & \mathrm{V} \\ \mathrm{V} & \mathrm{V}\end{array}$

$\mathrm{V} \quad \mathrm{v}$

$\begin{array}{ll}\mathrm{V} & \mathrm{V} \\ & \mathrm{V}\end{array}$

v $\quad \mathrm{v} \quad \mathrm{v}$

$\mathrm{v}$

$\begin{array}{lll}\mathrm{V} & \mathrm{V} & \mathrm{V}\end{array}$

$\mathrm{V} \quad \mathrm{V}$

V V

$\mathrm{V}-\mathrm{V}$

$\mathrm{V} \quad \mathrm{V}$

$\mathrm{V} \quad \mathrm{V}$

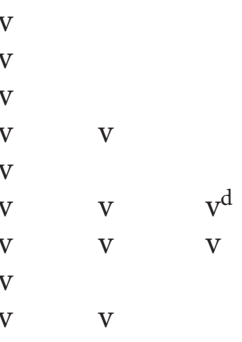

LPS concentration: whole blood samples were incubated with LPS for $24 \mathrm{~h}$ at $37^{\circ} \mathrm{C} . \mathrm{n} / \mathrm{a}$, not available; LPS, lipopolysaccharide; TNF- $\alpha$, tumour necrosis factor- $\alpha$; IL, interleukin; IFN- $\gamma$, interferon- $\gamma$; GM-CSF, granulocyte-macrophage colony-stimulating factor. ${ }^{a}$ LPS was incubated for $6 \mathrm{~h} .{ }^{\mathrm{b}}$ LPS was incubated for $4 \mathrm{~h} .{ }^{\mathrm{c}} 1 \mu \mathrm{g} / \mathrm{mL}$ LPS was used. ${ }^{\mathrm{d}} 50 \mu \mathrm{g} / \mathrm{mL}$ LPS was used.

and sex and age as independent variables. Some study populations included subjects from the same family (Table 1). The linear regression analyses of the data from these study populations were adjusted for family relationships between subjects by use of a family clustering factor as a sandwich estimator.

Random-effects meta-analyses were performed to estimate the overall ln-transformed difference in cytokine production response between men and women. The overall ratio of men over women in cytokine production response and its $95 \%$ confidence interval (CI) were calculated using an anti-log transformation of the overall lntransformed difference in cytokine production response between men and women and its 95\% CI.

Random-effects metaregression analyses were performed to investigate the effect of chronological age on the ratio of men over women in cytokine production response. These analyses were performed using study populations from the general population only, so that the possible sex-specific effects of specific diseases and their treatments on age-related changes in cytokine production response could not affect our results. For these analyses, each study population was stratified by age decade. The mean ratio of men over women in cytokine production response of proinflammatory cytokines was obtained by averaging the ratio of men over women in cytokine production response for TNF- $\alpha$, IL-6, IL-12, and IL- $1 \beta$. The mean ratio of men over women in cytokine production response of anti-inflammatory cytokines was obtained by averaging the ratio of men over women in cytokine production response of IL-1RA and IL-10. If data for a cytokine were missing, data on the available cytokines were used to calculate the mean ratio of men over women in cytokine production response.

Cytokine Production Capacity and Sex
To investigate the effect of normalization for monocyte concentration on sex differences in cytokine production response, we normalized the levels of produced cytokines for the monocyte concentration. Normalization was performed by dividing the cytokine level (in $\mathrm{pg} / \mathrm{L}$ ) by the monocyte concentration (in count $\times 10^{9} / \mathrm{L}$ ).

\section{Results}

Table 1 shows the characteristics of the included study populations. Ten study populations included subjects from the general population $(n=3,114)$ and 5 study populations included subjects with specific diseases $(n=906)$. The mean age of the subjects of the various study populations ranged from 21 to 85 years. The age of the individual subjects ranged from 3 to 95 years. The mean percentage of men among the study populations ranged from 18.6 to $74.2 \%$. Online supplementary Tables $1 \mathrm{~A}$ and $1 \mathrm{~B}$ (see www.karger.com/doi/10.1159/000499840, for all online suppl. material) show the crude cytokine production response values for the men and women in the included study populations.

Figure 1 shows forest plots of the ratios of men over women in cytokine production response for the proinflammatory cytokines TNF- $\alpha$, IL- 6 , IL- 12 , and IL- $1 \beta$. The 


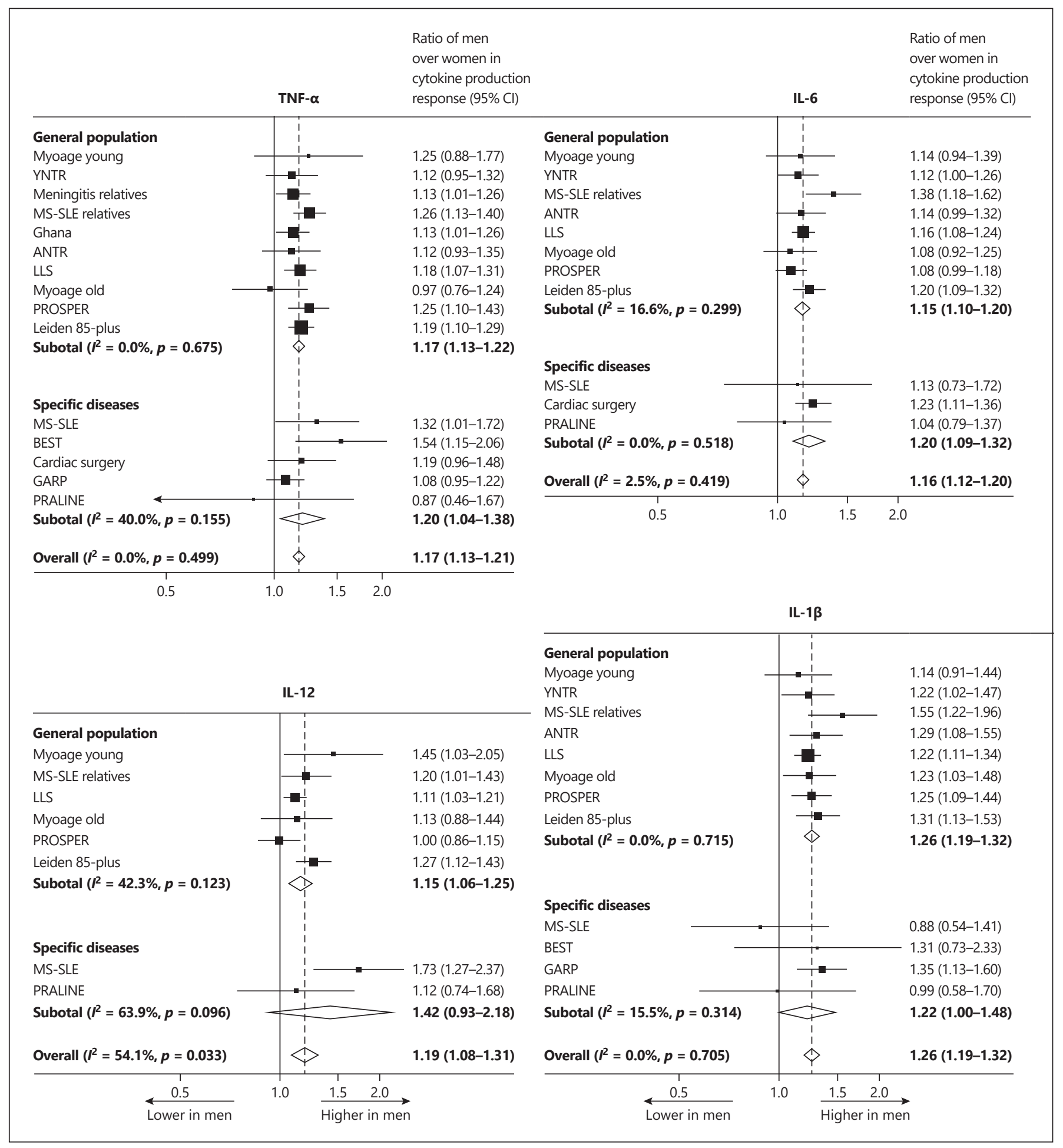

Fig. 1. Forest plots of the ratios of men over women in cytokine production response of proinflammatory cytokines. For the populations listed, see Table 1. 


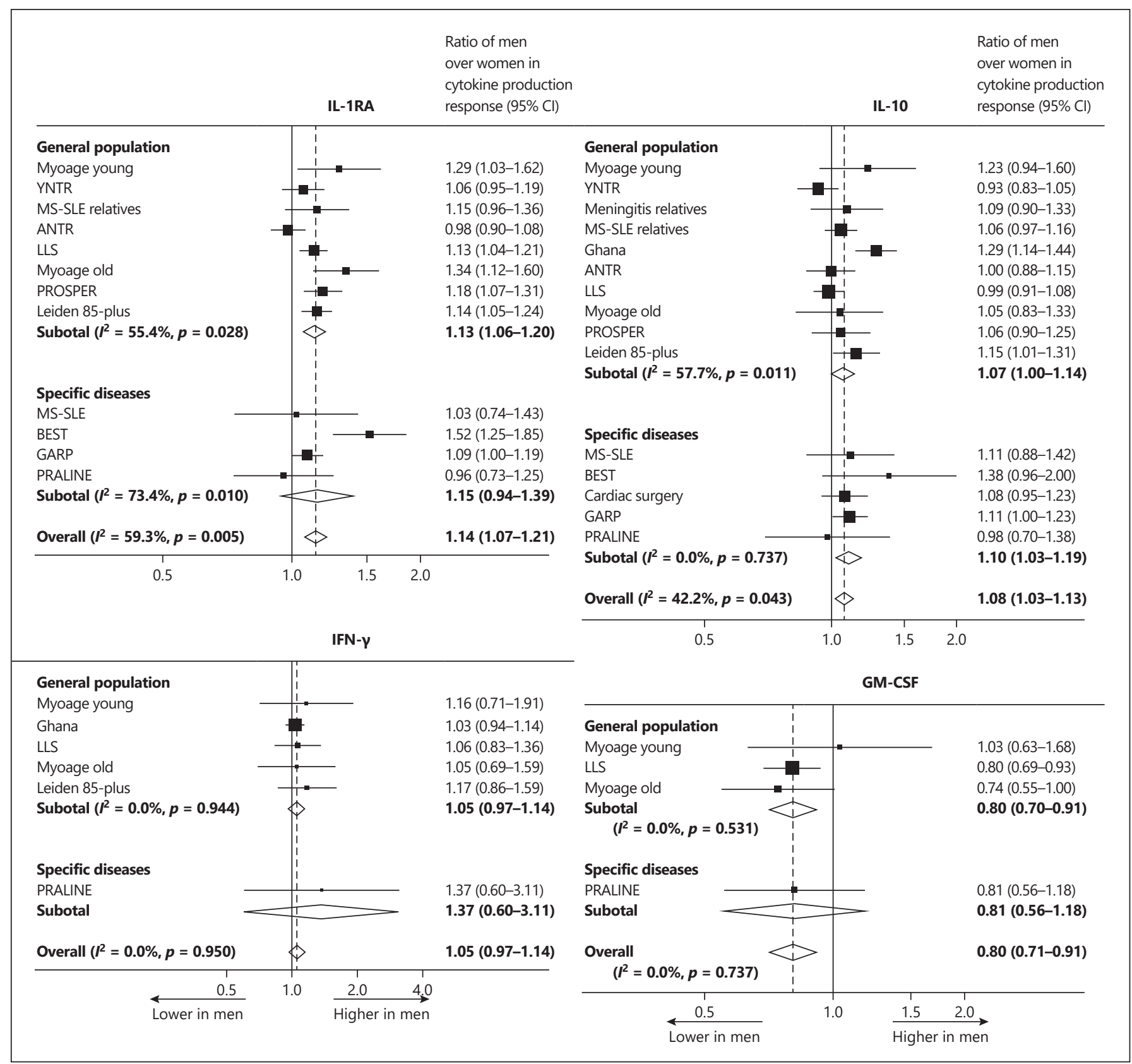

Fig. 2. Forest plots of the ratios of men over women in cytokine production response of anti-inflammatory cytokines and cytokines that stimulate proinflammatory cytokine production. For the populations listed, see Table 1.

cytokine production response of all cytokines was higher in men than in women (all $p<0.001)$. Figure 2 shows the forest plots of the ratios of men over women in cytokine production response for the anti-inflammatory cytokines IL-1RA and IL-10, as well as for the cytokines that stimulate proinflammatory cytokine production, i.e., IFN- $\gamma$ and GM-CSF. The cytokine production response of IL-
1RA and IL-10 was stronger in men than in women $(p<$ 0.001 and $p<0.05$, respectively). No significant sex differences in cytokine production response of IFN- $\gamma$ were found ( $p=0.23)$. The cytokine production response of GM-CSF was lower in men than in women $(p<0.001)$. The results for the study populations including subjects from the general population were not significantly differ- 


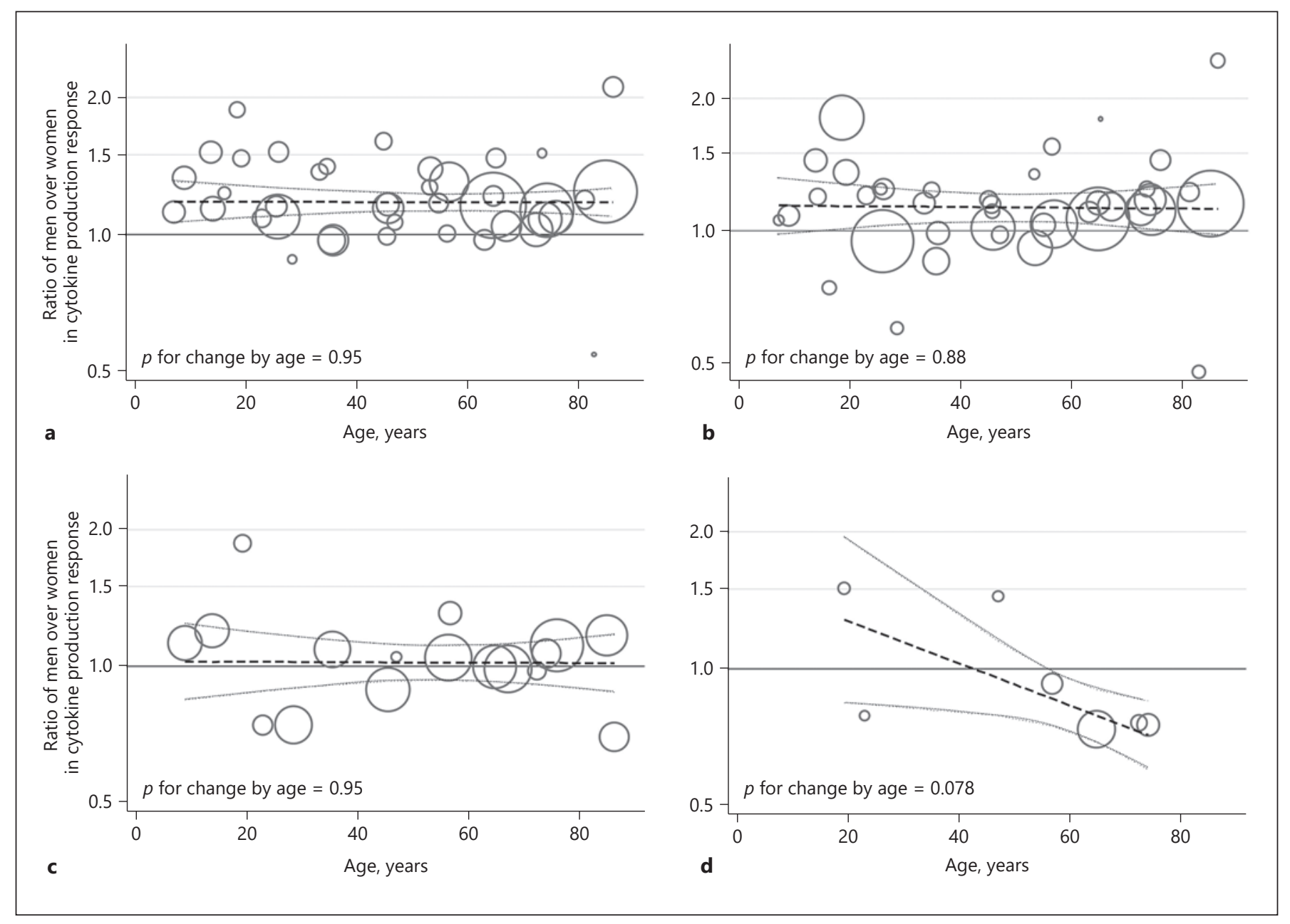

Fig. 3. Ratios of men over women in cytokine production response by chronological age. Scatter plots of the study populations from the general population stratified for age decade with meta-regression lines with $95 \%$ confidence intervals. A larger circle size indicates a higher precision of the estimate $\left(\right.$ circle size $\left.=1 / \mathrm{SE}^{2}\right)$. An estimate represents the mean of the ratio of men over women in cytokine production response for proinflammatory cytokines (tumour necrosis factor- $\alpha$, interleukin [IL]-6, IL-12, and IL-1 $\beta)(n=$ 40) (a), anti-inflammatory cytokines (IL-1RA and IL-10) $(n=40)$ (b), interferon- $\gamma(n=17)(\mathbf{c})$, and granulocyte-macrophage colony-stimulating factor $(n=7)(\mathbf{d})$. ent from those for the study populations including subjects with specific diseases. It is noteworthy that an identical pattern was observed in a Ghanaian study including subjects of African descent living under adverse environmental conditions in Ghana, as well as in studies including subjects from Western populations.

Figure 3 shows the mean ratios of men over women in cytokine production response by chronological age for the study populations including subjects from the general population. The mean ratios of men over women in cytokine production response for the proinflammatory (TNF- $\alpha$, IL-6, IL-12, and IL-1 $\beta$ ) and anti-inflammatory cytokines (IL-1RA and IL-10), as well as for IFN- $\gamma$, did not change by age (all $p>0.87$ ). The mean ratio of men over women in cytokine production response for GMCSF was lower at higher ages, but not statistically significantly so ( $p$ value for change by age $=0.078$ ).

In 3 of the included study populations (Myoage young, Myoage old, and LLS), it was possible to explore whether the sex differences in cytokine production response were attributable to sex differences in monocyte concentrations, due to the availability of data on leukocyte differential concentrations. Online supplementary Table 2 shows the pooled leukocyte differential concentrations in men and women. The leukocyte concentrations did not differ between men and women. The neutrophil and 
Table 3. Pooled effect of monocyte concentration normalization on ratios of men over women in cytokine production response in 3 independent study populations (Myoage young, Myoage old, and LLS)

\begin{tabular}{|c|c|c|c|c|}
\hline & \multicolumn{2}{|c|}{ Not normalized for monocyte concentration } & \multicolumn{2}{|l|}{ Normalized for monocyte concentration } \\
\hline & $\begin{array}{l}\text { ratio of men over women in cytokine } \\
\text { production response }(95 \% \mathrm{CI})\end{array}$ & $p$ value & $\begin{array}{l}\text { ratio of men over women in cytokine } \\
\text { production response }(95 \% \mathrm{CI})\end{array}$ & $p$ value \\
\hline TNF- $\alpha$ & $1.14(1.02-1.28)$ & 0.021 & $0.98(0.86-1.13)$ & 0.79 \\
\hline IL-6 & $1.15(1.08-1.22)$ & $<0.001$ & $0.98(0.90-1.06)$ & 0.61 \\
\hline IL-12 & $1.14(1.04-1.24)$ & 0.007 & $1.09(1.00-1.20)$ & 0.053 \\
\hline IL- $1 \beta$ & $1.21(1.12-1.31)$ & $<0.001$ & $1.06(0.98-1.14)$ & 0.17 \\
\hline IL-1RA & $1.22(1.08-1.38)$ & 0.002 & $1.05(0.92-1.19$ & 0.47 \\
\hline IL-10 & $1.03(0.92-1.13)$ & 0.59 & $0.89(0.83-0.96)$ & 0.001 \\
\hline
\end{tabular}

Estimates were calculated using a meta-analysis model with random effects and corrected for age and family relationships between subjects. CI, confidence interval; TNF- $\alpha$, tumour necrosis factor- $\alpha$; IL, interleukin.

monocyte concentrations were higher in men than in women ( $p=0.008$ and $p<0.001$, respectively), while the lymphocyte concentration was lower in men than in women $(p<0.001)$. Therefore, the cytokine production responses of the cytokines that are mainly produced by monocytes (TNF- $\alpha$, IL-6, IL-12, IL-1 $\beta$, IL-1RA, and IL10) were normalized for the monocyte concentration in each subject. Table 3 shows that the pooled ratios of men over women in cytokine production response normalized for monocyte concentration for TNF- $\alpha$, IL-6, IL-12, IL$1 \beta$, and IL-1RA were not significantly different from unity, indicating the absence of sex differences when taking monocyte concentrations into account. The pooled ratio of men over women in cytokine production response normalized for monocyte concentration for IL-10 was 0.89 (95\% CI 0.83-0.96).

\section{Discussion}

In the present study we showed that men compared to women had a higher monocyte-derived cytokine production response upon stimulation with the gram-negative stimulus LPS for TNF- $\alpha$, IL-6, IL-12, IL-1 $\beta$, IL-1RA, and IL-10, but not for IFN- $\gamma$. The GM-CSF production response was lower in men. These sex differences did not differ by age. As men had higher monocyte concentrations, we normalized the cytokine production responses for monocyte concentration. No sex differences in cytokine production response per monocyte were found, except for IL-10, which was significantly lower in men.

Our findings are in agreement with other studies reporting a higher cytokine production response in men than in women after stimulation with gram-negative

Cytokine Production Capacity and Sex agents [13-20, 23]. However, these studies were either small or found differences only in relatively young and healthy subjects. Moreover, others did not find any sex differences [20-22]. We showed that sex differences in cytokine production response are present in healthy populations of all ages and are independent of specific diseases like osteoarthritis, rheumatoid arthritis, multiple sclerosis, systemic lupus erythematosus, or cardiac diseases warranting cardiac surgery. This finding is in agreement with a study including more than 500 relatively young healthy subjects [23]. Moreover, we found the same pattern of sex differences in Ghanaians of African descent living under adverse environmental conditions in Ghana. These findings confirm sex differences in cytokine production response to be a true biological phenomenon.

The measurement of cytokine production response upon stimulation with LPS is a model primarily designed to investigate immune responsiveness in sepsis. In patients with multiple injuries, a higher TNF- $\alpha$ and IL-6 production response on the first day of admission has been associated with a higher risk of developing severe sepsis [25]. We showed that the TNF- $\alpha$ and IL- 6 production responses are higher in men than in women, which could be one of the factors causing the higher incidence of sepsis among men [2], next to other factors like sex differences in tissue-derived cytokine production and antigen exposure [27]. In contrast, among sepsis patients the mortality risk has been shown to be lower in men than in women [4]. This could be explained by the observation that the majority of deaths from sepsis do not occur during the initial hyperinflammatory phase, but during the later immunosuppressive phase characterized by a reduced proinflammatory cytokine production response 
[28]. The IL- $1 \beta$ production response during the late phase of sepsis has been shown to be higher among sepsis survivors than among non-survivors [29]. We found a higher IL-1 $\beta$ production response in men than in women. However, we did not investigate whether this sex difference was still present during the late immunosuppressive phase among sepsis patients. If this were the case, it could be one of the factors causing the lower sepsis mortality risk in men.

Measurement of the cytokine production response upon stimulation with LPS has also been used as a model of immune responsiveness to non-infectious diseases. A low cytokine production response has, on the one hand, been associated with consequences of the aging process, such as mortality [30], metabolic syndrome, type 2 diabetes [31], lower serum triiodothyronine levels [32], and low muscle mass and strength [33]. On the other hand, a low cytokine production response has been associated with familial traits such as a negative family history of Alzheimer's disease [34], a less severe progression of osteoarthritis within sibling pairs with osteoarthritis at multiple sites [35], and a negative family history of systemic lupus erythematosus [11]. It is tempting to speculate about the contribution of sex differences in immune responsiveness to the sex differences in the incidence and prognosis of these diseases. However, it still needs to be elucidated whether the cytokine production response plays a causal role in the development or progression of these diseases.

This study is the first to describe the relation between chronological age and sex differences in cytokine production response. Sex differences are commonly attributed to the sex hormones and are expected to be reduced after menopause. However, we found that sex differences in cytokine production response are independent of chronological age and remain after menopause. These results are in contrast with those of a relatively small study showing that sex differences in TNF-a production response are present in young subjects but not in older adults [14]. Moreover, experimental studies on the effects of oestrogen, progesterone, and testosterone on cytokine production response report conflicting results [36]. Likely, sex differences are not caused by the activational (reversible) effects of sex hormones on monocytes, but by the organizational (permanent) effects of sex hormones on monocyte concentrations in the blood [37]. Alternatively, sex differences could also be independent of sex hormones and be caused by the effect of a sex-biased expression of $\mathrm{X}$ and $\mathrm{Y}$ genes in bone marrow cells [37].
Significant effects of sex on immunophenotypes have been previously reported, showing larger numbers of activated NK cells in men than in women and greater numbers of mucosal-associated invariant T (MAIT) cells in women than in men [38]. We found that the observed sex differences in cytokine production response are largely dependent on sex differences in monocyte concentration. In agreement with our findings, some authors have reported higher monocyte concentrations in men than in women [39], although others did not find any sex differences [40]. As observed by Aulock et al. [39], normalization of cytokine production responses for individual monocyte concentration largely cancelled sex differences for the majority of the cytokines in our study. It is currently unknown whether normalization of the cytokine production response for individual monocyte concentration increases the clinical relevance of the measurement. Whether cytokines are produced by a larger number of monocytes or whether there is an increased production of cytokines per monocyte should be the focus of further investigations [7]. This is especially relevant for studies investigating the effect of cytokine production response on other circulating immune cells such as lymphocytes, since produced cytokines influence these cells directly via their cytokine receptors. The same is true for the effect of cytokine production response on vascular endothelial cells, which are also known to have cytokine receptors that are able to induce vascular dysfunction [41]. However, the argument might be less relevant for studies investigating diseases such as cancer, where the monocytes infiltrate the tissue. In these cases, the cytokine production response is dependent on the number of monocytes available for infiltration, and therefore normalizing the cytokine production response for the individual monocyte concentration would be preferable.

Interestingly, we found that the IL-10 production response per monocyte is stronger in women than in men. In women, reproductive success has been described to be dependent on a strong IL-10 production response at the fetal-maternal interface [42]. Monocytes infiltrate into the uterine tissues during early gestation and significantly increase in number with the onset of labour [43]. However, it is not known whether reproductive success is associated with the number of infiltrating monocytes independently of their IL-10 production response.

The present study has several strengths. First, data from each individual subject were available. Second, a large variety of cytokines were measured in a large variety of study populations, including subjects within a broad age range and with different health conditions. Third, all 
cytokines were measured in our laboratory or in cooperation with our laboratory in a standardized manner. A limitation is that cytokine production response was measured using a specific ligand secreted by gram-positive bacteria. However, also other pathogens as well as trauma elicit the same inflammatory response, and TLR-4, the pathogen recognition receptor for LPS, is also known to recognize endogenous danger signals [44]. Furthermore, no other immune stimulation to other microbial ligands such as gram-positive bacteria, fungi, or viruses was used. Previous reports have shown that sex differences may vary depending on the stimulus [23]. It is also very unfortunate that we were not able to adjust the relation between sex and cytokine production for monocyte concentration in all cohorts, or to analyse the impact of factors inhibiting proinflammatory cytokines, due to unavailable data. Finally, in our analyses we only took age, sex, and disease state into account, but no other factors which might be different between sexes, such as BMI and lifestyle factors.

\section{Conclusions}

We showed that sex differences in immune responsiveness to the gram-positive stimulus LPS and differential leukocyte concentrations are profound and consistent. This finding underscores the notion that the immune systems of men and women are distinctly different and stresses the importance of taking sex into account when studying immune responsiveness. We postulate that a sex-based approach to intervention with the immune system is crucial for immunomodulatory therapies.

\section{Acknowledgements}

We thank Margo van Schie-Troost and Marja Kersbergen-van Oostrom for their excellent work on the whole blood stimulation assays. We also thank Robert Klautz for providing data on cardiac surgery patients.

\section{Statement of Ethics}

All subjects of all included cohorts have given written informed consent to be part of the study. The study protocols have been approved by the research institute's committee on human research.

\section{Disclosure Statement}

The authors declare that the research was conducted in the absence of any commercial or financial relationships that could be construed as a potential conflict of interest.

\section{Funding Sources}

This study was funded by an unrestricted grant from the Board of Leiden University Medical Center. The included studies were funded by the Seventh Framework Programme MYOAGE, HEALTH-2007-2.4.5-10 (Myoage young study and Myoage old study); the Prof. Dr. Kassenaar Fund and the Praeventiefonds, M.28-2293 (Meningitis relatives study); the Dutch Society for Support of Research into Multiple Sclerosis, 96-229 MS (MS-SLE relatives and MS-SLE); the Netherlands Foundation for the Advancements of Tropical Research, WOTRO 93-467, Stichting Dioraphte, and the Netherlands Organization for Scientific Research, NWO 051-14-050 (Ghana study); the European Union-funded Network of Excellence LifeSpan, FP6 036894 (Ghana study, Leiden 85-plus study); the Netherlands Genomics/Netherlands Organization for Scientific Research, NGI/NWO, 05040202 and 050-060-810 NCHA (LLS and Leiden 85-plus study); Bristol-Myers Squibb, USA (PROSPER study); the Dutch College for Health Insurance Companies and Centocor and Schering-Plough (BEST); and Pfizer Inc., Groton, CT, USA (GARP study).

\section{Author Contributions}

K.G.M.B., R.G.J.W., S.C., Y.R., and A.B.M. developed the concept of this study. R.G.J.W., A.J.M.d.C., B.E.P.B.B., R.G.H.H.N., A.F.L.L., T.W.H., P.E.S., D.I.B., and A.B.M. collected the data for the study. The first draft of the manuscript was written by K.G.M.B. and revised by R.G.J.W., A.J.M.d.C., S.C., Y.R., B.E.P.B.B., R.G.H.H.N., A.F.L.L., T.W.H., P.E.S., D.I.B., and A.B.M.

\section{References}

1 Offner PJ, Moore EE, Biffl WL. Male gender is a risk factor for major infections after surgery. Arch Surg. 1999 Sep;134(9):935-8; discussion 938-40.

2 Dombrovskiy VY, Martin AA, Sunderram J, Paz HL. Rapid increase in hospitalization and mortality rates for severe sepsis in the United States: a trend analysis from 1993 to 2003 . Crit Care Med. 2007 May;35(5):1244-50.
3 Whitacre CC. Sex differences in autoimmune disease. Nat Immunol. 2001 Sep;2(9):777-80.

4 Nachtigall I, Tafelski S, Rothbart A, Kaufner L, Schmidt M, Tamarkin A, et al. Gender-related outcome difference is related to course of sepsis on mixed ICUs: a prospective, observational clinical study. Crit Care. 2011 Jun; 15(3):R151.
5 Aguirre-Gamboa R, Joosten I, Urbano PCM, van der Molen RG, van Rijssen E, van Cranenbroek B, et al. Differential Effects of Environmental and Genetic Factors on T and B Cell Immune Traits. Cell Rep. 2016 Nov; 17(9): 2474-87. 
6 McKean KA, Nunney L. Bateman's principle and immunity: phenotypically plastic reproductive strategies predict changes in immunological sex differences. Evolution. 2005 Jul; 59(7):1510-7.

7 van der Linden MW, Huizinga TW, Stoeken DJ, Sturk A, Westendorp RG. Determination of tumour necrosis factor-alpha and interleukin-10 production in a whole blood stimulation system: assessment of laboratory error and individual variation. J Immunol Methods. 1998 Sep;218(1-2):63-71.

8 Damsgaard CT, Lauritzen L, Calder PC, Kjaer TM, Frøkiaer H. Whole-blood culture is a valid low-cost method to measure monocytic cytokines - a comparison of cytokine production in cultures of human whole-blood, mononuclear cells and monocytes. J Immunol Methods. 2009 Jan;340(2):95-101.

9 de Craen AJ, Posthuma D, Remarque EJ, van den Biggelaar AH, Westendorp RG, Boomsma DI. Heritability estimates of innate immunity: an extended twin study. Genes Immun. 2005 Mar;6(2):167-70.

10 Westendorp RG, Langermans JA, Huizinga TW, Elouali AH, Verweij CL, Boomsma DI, et al. Genetic influence on cytokine production and fatal meningococcal disease. Lancet. 1997 Jan;349(9046):170-3.

11 van der Linden MW, Westendorp RG, Sturk A, Bergman W, Huizinga TW. High interleukin-10 production in first-degree relatives of patients with generalized but not cutaneous lupus erythematosus. J Investig Med. 2000 Sep;48(5):327-34.

12 de Jong BA, Huizinga TW, Bollen EL, Uitdehaag BM, Bosma GP, van Buchem MA, et al. Production of IL-1beta and IL-1Ra as risk factors for susceptibility and progression of relapse-onset multiple sclerosis. J Neuroimmunol. 2002 May;126(1-2):172-9.

13 Almeida M, Ribeiro O, Aragão I, CostaPereira A, Cardoso T. Differences in compliance with Surviving Sepsis Campaign recommendations according to hospital entrance time: day versus night. Crit Care. 2013 Apr; 17(2):R79.

14 Bruunsgaard H, Pedersen AN, Schroll M, Skinhoj P, Pedersen BK. Impaired production of proinflammatory cytokines in response to lipopolysaccharide (LPS) stimulation in elderly humans. Clin Exp Immunol. 1999 Nov; 118(2):235-41.

15 Lefèvre N, Corazza F, Duchateau J, Desir J, Casimir G. Sex differences in inflammatory cytokines and CD99 expression following in vitro lipopolysaccharide stimulation. Shock. 2012 Jul;38(1):37-42.

16 Kim-Fine S, Regnault TR, Lee JS, Gimbel SA, Greenspoon JA, Fairbairn J, et al. Male gender promotes an increased inflammatory response to lipopolysaccharide in umbilical vein blood. J Matern Fetal Neonatal Med. 2012 Nov;25(11):2470-4.
17 Heesen M, Bloemeke B, Heussen N, Kunz D. Can the interleukin- 6 response to endotoxin be predicted? Studies of the influence of a promoter polymorphism of the interleukin-6 gene, gender, the density of the endotoxin receptor CD14, and inflammatory cytokines. Crit Care Med. 2002 Mar;30(3):664-9.

18 Auger G, Corvec S, Roquilly A, Segain JP, Lepelletier D, Reynaud A, et al. Escherichia coliinduced productions of pro-inflammatory cytokines are regulated by MAP kinases and G-protein but not by Akt: relationship with phylogenetic groups and resistance patterns. Cytokine. 2011 Nov;56(2):290-7.

19 Balteskard L, Brox JH, Osterud B. Thromboxane production in the blood of women increases after menopause whereas tumor necrosis factor is reduced in women compared with men. Atherosclerosis. 1993 Aug;102(1): 91-8.

20 Imahara SD, Jelacic S, Junker CE, O’Keefe GE The influence of gender on human innate immunity. Surgery. 2005 Aug;138(2):275-82.

21 Lynch EA, Dinarello CA, Cannon JG. Gender differences in IL-1 alpha, IL-1 beta, and IL-1 receptor antagonist secretion from mononuclear cells and urinary excretion. J Immunol. 1994 Jul;153(1):300-6.

22 Moxley G, Stern AG, Carlson P, Estrada E, Han J, Benson LL. Premenopausal sexual dimorphism in lipopolysaccharide-stimulated production and secretion of tumor necrosis factor. J Rheumatol. 2004 Apr;31(4):686-94.

23 Ter Horst R, Jaeger M, Smeekens SP, Oosting M, Swertz MA, Li Y, et al. Host and Environmental Factors Influencing Individual $\mathrm{Hu}$ man Cytokine Responses. Cell. 2016 Nov; 167(4):1111-1124.e13.

24 Rittersma SZ, Kremer Hovinga JA, Koch KT, Boekholdt SM, van Aken BE, Scheepmaker A, et al. Relationship between in vitro lipopolysaccharide-induced cytokine response in whole blood, angiographic in-stent restenosis, and toll-like receptor 4 gene polymorphisms. Clin Chem. 2005 Mar;51(3):516-21.

25 Majetschak M, Christensen B, Obertacke U, Waydhas C, Schindler AE, Nast-Kolb D, et al. Sex differences in posttraumatic cytokine release of endotoxin-stimulated whole blood: relationship to the development of severe sepsis. J Trauma. 2000 May;48(5):832-9; discussion 839-40.

26 Scheingraber S, Dobbert D, Schmiedel P, Seliger E, Dralle H. Gender-specific differences in sex hormones and cytokines in patients undergoing major abdominal surgery. Surg Today. 2005;35(10):846-54.

27 van Eijk LT, Dorresteijn MJ, Smits P, van der Hoeven JG, Netea MG, Pickkers P. Gender differences in the innate immune response and vascular reactivity following the administration of endotoxin to human volunteers. Crit Care Med. 2007 Jun;35(6):1464-9.
28 Hotchkiss RS, Monneret G, Payen D. Immunosuppression in sepsis: a novel understanding of the disorder and a new therapeutic approach. Lancet Infect Dis. 2013 Mar;13(3): 260-8.

29 Weighardt H, Heidecke CD, Emmanuilidis K, Maier S, Bartels H, Siewert JR, et al. Sepsis after major visceral surgery is associated with sustained and interferon-gamma-resistant defects of monocyte cytokine production. Surgery. 2000 Mar;127(3):309-15.

30 Wijsman CA, Maier AB, de Craen AJ, van den Biggelaar AH, Westendorp RG. An unopposed proinflammatory response is beneficial for survival in the oldest old. Results of the Leiden 85-plus Study. J Gerontol A Biol Sci Med Sci. 2011 Apr;66(4):393-9.

31 van Exel E, Gussekloo J, de Craen AJ, Frölich M, Bootsma-Van Der Wiel A, Westendorp RG; Leiden 85 Plus Study. Low production capacity of interleukin-10 associates with the metabolic syndrome and type 2 diabetes: the Leiden 85-Plus Study. Diabetes. 2002 Apr; 51(4):1088-92.

32 Rozing MP, Westendorp RG, Maier AB, Wijsman CA, Frölich M, de Craen AJ, et al. Serum triiodothyronine levels and inflammatory cytokine production capacity. Age (Dordr). 2012 Feb;34(1):195-201.

33 Beenakker KG, Westendorp RG, de Craen AJ, Slagboom PE, van Heemst D, Maier AB. Proinflammatory capacity of classically activated monocytes relates positively to muscle mass and strength. Aging Cell. 2013 Aug;12(4): 682-9.

34 van Exel E, Eikelenboom P, Comijs H, Frölich M, Smit JH, Stek ML, et al. Vascular factors and markers of inflammation in offspring with a parental history of late-onset Alzheimer disease. Arch Gen Psychiatry. 2009 Nov; 66(11):1263-70.

35 Botha-Scheepers S, Watt I, Slagboom E, de Craen AJ, Meulenbelt I, Rosendaal FR, et al. Innate production of tumour necrosis factor alpha and interleukin 10 is associated with radiological progression of knee osteoarthritis. Ann Rheum Dis. 2008 Aug;67(8):1165-9.

36 Bouman A, Heineman MJ, Faas MM. Sex hormones and the immune response in humans. Hum Reprod Update. 2005 Jul-Aug;11(4): 411-23.

37 Arnold AP. The organizational-activational hypothesis as the foundation for a unified theory of sexual differentiation of all mammalian tissues. Horm Behav. 2009 May;55(5):570-8.

38 Patin E, Hasan M, Bergstedt J, Rouilly V, Libri V, Urrutia A, et al.; Milieu Intérieur Consortium. Natural variation in the parameters of innate immune cells is preferentially driven by genetic factors. Nat Immunol. $2018 \mathrm{Mar}$; 19(3):302-14.

39 Aulock SV, Deininger S, Draing C, Gueinzius K, Dehus O, Hermann C. Gender difference in cytokine secretion on immune stimulation with LPS and LTA. J Interferon Cytokine Res. 2006 Dec;26(12):887-92. 
40 Bain BJ, England JM. Normal haematological values: sex difference in neutrophil count. $\mathrm{Br}$ Med J. 1975 Feb;1(5953):306-9.

41 Sprague AH, Khalil RA. Inflammatory cytokines in vascular dysfunction and vascular disease. Biochem Pharmacol. 2009 Sep;78(6): 539-52.

42 Westendorp RG, van Dunne FM, Kirkwood TB, Helmerhorst FM, Huizinga TW. Optimizing human fertility and survival. Nat Med. 2001 Aug;7(8):873.

43 Gomez-Lopez N, Guilbert LJ, Olson DM. Invasion of the leukocytes into the fetal-maternal interface during pregnancy. J Leukoc Biol. 2010 Oct;88(4):625-33.

44 Bianchi ME, Manfredi AA. Immunology. Dangers in and out. Science. 2009 Mar; 323(5922):1683-4.

45 McPhee JS, Hogrel JY, Maier AB, Seppet E, Seynnes OR, Sipilä S, et al. Physiological and functional evaluation of healthy young and older men and women: design of the European MyoAge study. Biogerontology. 2013 Jun;14(3):325-37.
46 Boomsma DI, de Geus EJ, Vink JM, Stubbe JH, Distel MA, Hottenga JJ, et al. Netherlands Twin Register: from twins to twin families. Twin Res Hum Genet. 2006 Dec;9(6):849-57.

47 May L, van Bodegom D, Kuningas M, Meij JJ, de Craen AJ, Frölich M, et al. Performance of the whole-blood stimulation assay for assessing innate immune activation under field conditions. Cytokine. 2009 Mar;45(3):184-9.

48 Trompet S, de Craen AJ, Mooijaart S, Stott DJ, Ford I, Sattar N, et al. High Innate Production Capacity of Proinflammatory Cytokines Increases Risk for Death from Cancer: results of the PROSPER Study. Clin Cancer Res. 2009 Dec;15(24):7744-8.

49 van den Biggelaar AH, Huizinga TW, de Craen AJ, Gussekloo J, Heijmans BT, Frölich $\mathrm{M}$, et al. Impaired innate immunity predicts frailty in old age. The Leiden 85-plus study. Exp Gerontol. 2004 Sep;39(9):1407-14.

50 Later AF, Maas JJ, Engbers FH, Versteegh MI, Bruggemans EF, Dion RA, et al. Tranexamic acid and aprotinin in low- and intermediaterisk cardiac surgery: a non-sponsored, dou- ble-blind, randomised, placebo-controlled trial. Eur J Cardiothorac Surg. 2009 Aug; 36(2):322-9.

51 Riyazi N, Meulenbelt I, Kroon HM, Ronday $\mathrm{KH}$, Hellio le Graverand MP, Rosendaal FR, et al. Evidence for familial aggregation of hand, hip, and spine but not knee osteoarthritis in siblings with multiple joint involvement: the GARP study. Ann Rheum Dis. 2005 Mar; 64(3):438-43.

52 Schoeman MA, Pijls BG, Oostlander AE, Keurentjes JC, Valstar ER, Nelissen RG, et al. Innate immune response and implant loosening: interferon gamma is inversely associated with early migration of total knee prostheses. J Orthop Res. 2016 Jan;34(1):121-6.

53 de Vries-Bouwstra JK, Goekoop-Ruiterman YP, Wesoly J, Hulsmans HJ, de Craen AJ, Breedveld FC, et al. Ex vivo interleukin 1 receptor antagonist production on lipopolysaccharide stimulation is associated with rheumatoid arthritis and with joint damage. Ann Rheum Dis. 2007 Aug;66(8): 1033-7. 